\title{
Fracture strength in cleavage of epoxy/alumina nanocomposite adhesives in bonded aluminium joints
}

\author{
Manish Kumar Singh, Dharmendra Kumar Shukla* and Sunil Kumar Gupta
}

\author{
Department of Mechanical Engineering, Motilal Nehru National Institute of Technology Allahabad, \\ Allahabad-211004, India \\ *Email:dkshukla@mnnit.ac.in
}

Epoxy based adhesives are extensively used for joining of structural members. Reinforcement of nanoparticles in adhesives is one of the possible method to increase the properties $[1,2]$. In the present study, epoxy reinforced with alumina nanorods (having diameter in the range of $10 \mathrm{~nm}$ and length less than $50 \mathrm{~nm}$ ) has been used as adhesive and the effect of wt.\% of nanoparticles on mode I fracture toughness of nanocomposite adhesive was determined. Mode I fracture toughness of epoxy/alumina nanocomposite adhesives in bonded aluminium joints was determined using a double cantilever beam specimen following the ASTM standard D3433-99 [3]. Aluminium (elastic modulus $70 \mathrm{GPa}$, Yield strength $100 \mathrm{MPa}$ ) was used as adherend material. Aluminium adherends having length $356 \mathrm{~mm}$, width $25.4 \mathrm{~mm}$ and thickness 12.7 $\mathrm{mm}$ were used to prepare the joint with non adhesive shim up to $51 \mathrm{~mm}$. Bisphenol-A based epoxy Araldite LY556 ${ }^{\circledR}$ along with polyamine Hardener HY $951^{\circledR}$ was used as base adhesive. Alumina $\left(\mathrm{Al}_{2} \mathrm{O}_{3}\right)$ nanoparticles having density $4 \mathrm{~g} / \mathrm{cm}^{3}$ and specific surface area $40 \mathrm{~m}^{2} / \mathrm{g}$ were used as reinforcement. Ultrasonication technique was used to disperse the nanoparticles in epoxy resin during the synthesis of epoxy/alumina nanocomposite adhesives. The nanocomposites having $0.5,1.0,1.5$, 2.0 wt.\% nanoparticles (alumina nanorods) were used as the adhesives.

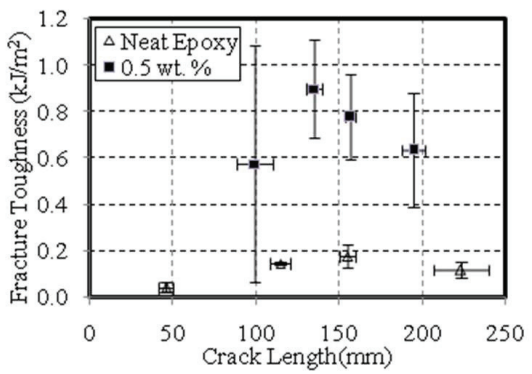

Figure 1: Fracture toughness as a function of crack length for neat epoxy and $0.5 \mathrm{wt} \% \%$ alumina nanorod composite

Fracture toughness of neat epoxy and nanocomposite adhesive having 0.5 wt. $\%$ of alumina nanorod as a function of crack length is shown in Figure 1. Reinforcement of nanoparticles increased fracture toughness of adhesively bonded joints. Fracture toughness of nanocomposites having
0.5 wt.\% alumina nanorods were increased by 5 to 10 times in comparison to that of neat epoxy at various crack lengths. Figure 2 shows the average fracture toughness of adhesives as a function of wt.\% of alumina nanorods. Average Fracture toughness for neat epoxy was $119.41 \mathrm{~J} / \mathrm{m}^{2}$ while that of nanocomposite adhesive having 0.5 wt.\% of nanorods was $720.15 \mathrm{~J} / \mathrm{m}^{2}$ (an increment of $503 \%$ ). Fracture toughness decreased when wt.\% of alumina nanorods was increased beyond 0.5 wt. \%, (i.e. at 1.0, 1.5, and 2.0 wt.\%). However the average fracture toughness of nanocomposite adhesive at $1.0,1.5$, and $2.0 \mathrm{wt} . \%$ of nanorods was higher than that of average fracture toughness of neat epoxy adhesive. No significant change in fracture toughness of adhesive was observed when wt.\% of nanorods was increased beyond $1.0 \%$. The decrease in the fracture toughness of alumina nanorods could be attributed to agglomeration of nanorods at higher wt.\%. The mode of cohesive and interfacial failures was analyzed on fracture surfaces of joints. Mixed mode of failures was observed for all types of adhesives. However the cohesive failure in nanocomposites adhesive having $0.5 \mathrm{wt} \%$ of nanorods was comparatively higher than that of neat and reinforced epoxy (1.0, 1.5 and $2.0 \mathrm{wt} . \%$ of nanorods).

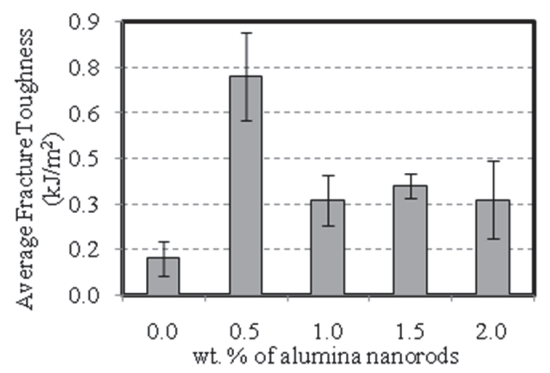

Figure 2: Average fracture toughness as function of wt.\% of alumina nanorods

\section{References}

1. A. Buchman, H. D. Kenig, A. Dotan, R. Tenne, S. Kenig, J. Adhes. Sci. Technol. 23 (2009) 753.

2. Q. Meng, C. H. Wang, N. Saber, H. C. Kuan, J. Dai, K. Friedrich, J. Ma, Mater. Des. 61 (2014) 75.

3. ASTM Standard D3433-99, "Fracture strength in cleavage of adhesives in bonded metal joints"' 2012. 